\title{
Wikipedia at the University: engaging students and teachers in open knowledge and collaborative work
}

\author{
Teresa Martín-García ${ }^{1}$, Fernando Almaraz-Menéndez ${ }^{2}$, Carmen López-Esteban $^{3}$ \\ ${ }^{1}$ Faculty of Sociology and Communication, University Salamanca, Spain, ${ }^{2}$ Faculty of \\ Economics and Business, University Salamanca, Spain, ${ }^{3}$ Faculty of Education, University \\ Salamanca, Spain.
}

\begin{abstract}
In the last decade, Wikipedia has gone from being one of the great enemies of education to becoming a great ally, especially thanks to the degree of rigour and organisation it has achieved. The free encyclopaedia is increasingly present in universities and offers numerous opportunities for teachers for educational innovation.

This paper describes an innovation project promoted by MediaLab USAL at the University of Salamanca and aimed at the generation and publication of open knowledge, at university level, in the open encyclopaedia Wikipedia.

This project aims to promote the creation of quality content in Spanish at the University, to include the rigorous editing of content in Wikipedia as part of the practical work of undergraduate and postgraduate subjects at the University of Salamanca and to offer a new free learning tool to teachers and students. The initiative has counted with the participation of more than 100 professors, 584 students and has achieved the creation of 1752 articles specialised in different areas of knowledge in Wikipedia.
\end{abstract}

Keywords: Wikipedia; educational innovation; collaborative work, open knowledge. 


\section{Introduction}

Wikipedia is one of the most visited websites on the Internet, despite the fact that in recent years it has not stopped losing visits, due to the impact of Google's smart search, which gives priority to its own platforms such as YouTube. Nevertheless, it is still the fourth most visited website in the world (Alexa, 2020).

Wikipedia began its journey in 2001 and, since then, it has not stopped growing, becoming a place of reference for all kinds of queries. The Spanish edition of Wikipedia is one of the most successful, with more than 31 million visits per day (Wikipedia, 2021), many of them coming from the field of Higher Education (according to the statistics currently offered by Wikipedia itself). However, for a long time this global encyclopaedia has been stigmatised in the educational world, precisely because of its open and collaborative nature. "The main concerns that teachers have about Wikipedia are quality, accuracy and reliability", (Meseguer-Artola, 2015).

Wikipedia has developed a rigorous publication process and currently the publications made by contributors are checked using wiki technology (which allows collaborative work from a technical point of view) and the crowdsourcing production model, on which the work of the volunteers who review the content is based, among other actions (Alonso-Jiménez, 2015).

The educational use of wikis has become popular due to the variety of didactic uses it offers (Villarroel, 2007) and for being an excellent resource for transforming the process of transmission and reception of knowledge in a context marked by information and connectivity (Legaz and Morales, 2018).

The interest that this open encyclopaedia continues to arouse as a source of open information and its collaborative work formula make Wikipedia the ideal environment for experimentation and teaching innovation. Based on these premises and as part of a teaching innovation project, this experience was developed with students of Art History at the University of Salamanca.

\section{WikiUSAL: A proposal for educational innovation with Wikipedia in the medialab of the University of Salamanca}

\subsection{MEDIALAB USAL. A space for educational innovation at the University}

This teaching initiative has been developed by MEDIALAB USAL, a space created at the University of Salamanca in 2010 to promote educational experimentation and innovation. In addition to fostering innovative experiences, the University of Salamanca's medialab promotes experimentation with digital technologies, the promotion of creativity and 
interdisciplinary work; typical elements of social laboratories for university innovation (Romero and Robinson, 2017).

Along with these characteristics, one of the main tasks of the medialab of the University of Salamanca is to promote the philosophy of collaborative work from a practical point of view and using open source digital tools; aspects acquired from the culture of the commons and which enable collective cultural creation (Escaño, 2017; Méndez, 2015; Lucero, 2003).

MEDIALAB USAL was created with the intention of favouring the connection between teachers, students, technology and digital media. Above all, it is a project that seeks to respond to the needs of the new educational model. Therefore, it seeks the active participation of students and teachers and, for this reason, all its projects and programme of activities have been conceived from a very practical and immersive point of view, since, as José M. Ruíz (2016) points out in one of his research projects, the medialab model "represents a highly interesting example to carry out the necessary study on the change in the educational and cultural model -which began with the end of mass media-, in which the consumer -or student or collaborator- is transformed from a passive being to an active being, converting the communicative act into a constant feedback of information" (Ruíz, 2016: 103).

Since its beginnings, MEDIALAB USAL has contributed, among other aspects, to the creation of new virtual physical spaces for collaboration and generation of open knowledge among the university community (Almaraz-Menéndez et al., 2016).

\subsection{Wikipedia as a tool for educational innovation that promotes open knowledge and collaborative work}

As part of this collaborative activity in MEDIALAB USAL, a large teaching project called WikiUSAL was conceived in 2013, which has been developed for years, with the aim of contributing to the rigorous and specialised creation of content in Wikipedia from the University; an initiative in which more than 100 teachers from all areas of knowledge at the University of Salamanca joined, along with more than 600 students.

The teaching proposal included prior training of the participants in the inner workings of the free encyclopaedia, the rules of publication, forms of participation and the development of specialised content, among other aspects.

The project has its own web platform (http://diarium.usal.es/wiki/), designed to provide information on progress and to promote the creation of a wiki community at the University.

In addition, all the information and materials related to the activities and initiatives that have been launched, such as videos and presentations of conferences and workshops, have been published on this website. 
Along with the workshops, several tutorials on the publication rules and wiki code have been developed to support the participants, which at the same time have been shared freely with other interested people from the university community who were interested in learning how to edit in Wikipedia, in line with its philosophy of free and collaborative learning.

This great collaborative teaching innovation project of the University of Salamanca managed to create a community interested in Wikipedia editing and in its utilities as a teaching and learning methodology that gave rise to new proposals from students and teachers. Thus arose the initiative to make known the rich heritage of the University of Salamanca in Wikipedia through an editing workshop in the free encyclopaedia, which is detailed below.

\section{Wikiparty: Loci et imagines' at the University of Salamanca. Collaborative Wikipedia editing through artistic heritage}

To commemorate the 800 years of history of the University of Salamanca celebrated in 2018, the exhibition Loci et imagines/Images and Places of heritage at the University was organised, dedicated to showing the immense cultural and material heritage that the USAL has been treasuring over VIII centuries.

Despite the fact that many of the artistic pieces exhibited and the places highlighted in the exhibition were of great heritage and historical relevance, surprisingly there was no trace or mention of them in Wikipedia. For this reason, MEDIALAB USAL carried out an open and participatory proposal with teachers and students of the University to create content about these works in Wikipedia.

Due to its usefulness and attractiveness, the proposal was included in the official programme of activities to commemorate the 800 years of history of the University of Salamanca.

This activity was inspired by the working formula that is usually used in the hackathons that MEDIALAB USAL organise at the University to promote social innovation. These meetings are an excellent context to implement aspects such as collaborative work through projectbased learning. (Almaraz-Menéndez et al., 2016).

\subsection{Structure of the teaching activity 'Loci et Imagines wikipedia editing marathon'}

The main objectives of the activity, called 'Loci et imagines Wikipeida editing marathon', were to bring the University of Salamanca closer to the public outside the University and to promote the editing of rigorous content in Spanish on Wikipedia related to the University's heritage. To this end, the teachers and students of the Degree in Art History at the University of Salamanca were involved.

The proposal started with an explanatory tour by one of the participating lecturers, who was also in charge of curating the exhibition. After the exhibition tour, an informative seminar 
and a Wikipedia editing workshop were organised to teach students the formulas for creating and editing content in the encyclopaedia, as well as the rest of the operating rules.

Subsequently, teachers and students distributed the content to be edited and for a morning they created content linked to the most important elements and to the exhibition itself as a whole. Previously, as an additional activity, they had carried out documentary work on the different works.

Thanks to this activity, more than twenty articles were created on Wikipedia, related to the artistic and cultural heritage of the University of Salamanca. In addition, as a result of the editing marathon, 6 chapters of content related to the exhibition were created in Wikipedia: The City of Knowledge (about the beginnings of the University in the 13th century), The Royal Chapel of San Jerónimo, The Library. Culture and Science, the Portrait Gallery of Kings and Queens of Spain and the University and Secular Colleges. All of them are listed at the following address:

https://es.wikipedia.org/wiki/Loci_et_Imagines

Some of these places and pieces that did not have any article in Wikipedia are as important as the General Historical Library of the University of Salamanca, considered the first university library in Europe.

The activity was also very well received by the students and had an important repercussion among the university community and the press. 


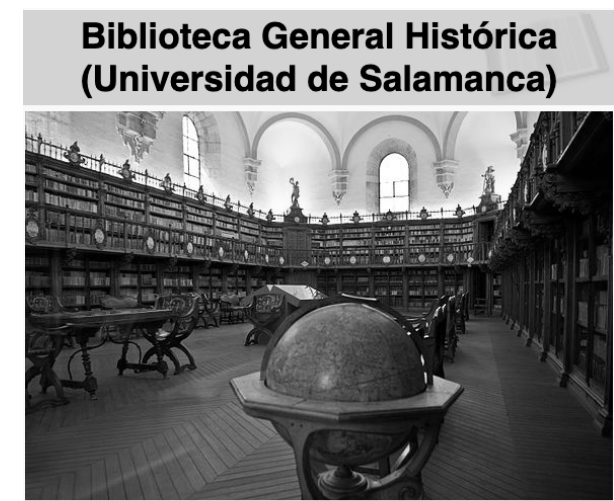

Vista general de la Biblioteca.

$\begin{array}{ll}\text { País } & \text { España } \\ \text { Tipo } & \text { biblioteca universitaria } \\ \text { Fundación } & 1254 \\ \text { Ubicación } & \text { Salamanca } \\ \text { Coordenadas } & 40^{\circ} 57^{\prime} 41.18^{\prime \prime} \mathrm{N}, 5^{\circ} 40^{\prime 2} 2.14 \text { "W } \\ \text { Entidad propietaria } & \text { Universidad de Salamanca }\end{array}$

Página web oficial 伃

[editar datos en Wikidata]

Figure 1. Wikipedia article of the General Historical Library of the USAL

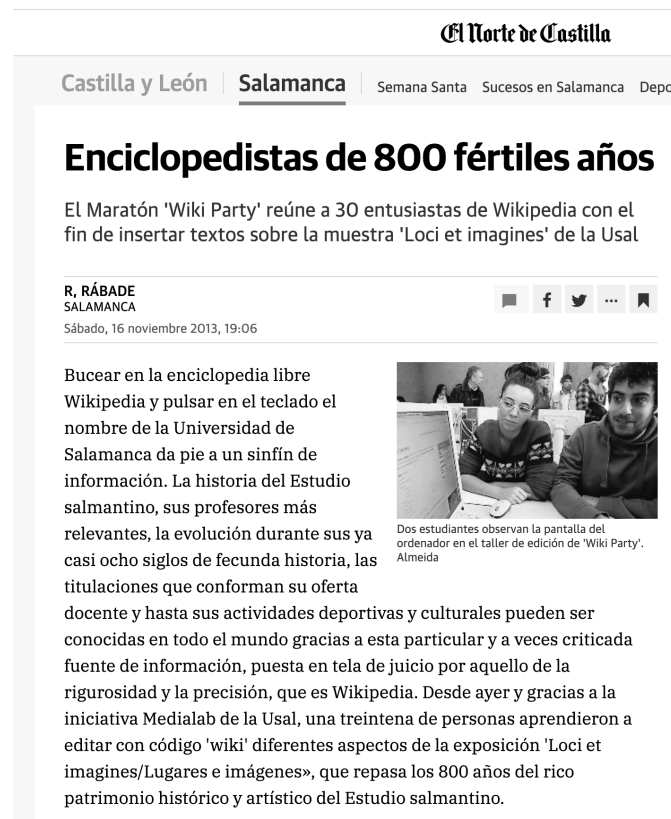

Figure 2. One of the press appearances of the Wikipedia teaching activity 


\section{Discussion}

The creation of this project has been an excellent opportunity to involve the university community in the creation of specialised and rigorous content in Spanish on Wikipedia, thus contributing to the growth of this global free encyclopaedia, whose queries and users continue to grow every day.

Undoubtedly, one of the main motivations for the involvement of the participants has been to be able to work in a real environment that is consulted by millions of people every day. This project has enabled students to present some of their academic work to a global audience, making them feel, among other things, more responsible for work of great practical utility that would otherwise not leave the classroom.

Also, by being in an open community, their work can continue to improve, transform and grow once the task is completed. These aspects help both teachers and students to integrate the principles of a free and collaborative knowledge environment.

Moreover, being part of such a project reinforces students' ability to think critically and evaluate different sources of information, which is essential in a context of information saturation and false content on the Internet.

\section{References}

Almaraz-Menéndez, F., Gimeno-González, M.A., Martín-García, T. (2016). Emerging digital technologies and new learning spaces. The case of $3 \mathrm{D}$ printing at the medialab of the university of Salamanca. INTED 2016 Proceedings.

Almaraz-Menéndez, F., Martín-García, T., Gimeno-González, M.A. (2017). Hackaton experiences at MEDIALAB USAL as a new university model of collaborative and problem-based learning. ICERI 2017 Proceedings.

Alonso, E. (2015). An approach to Wikipedia as a cultural polysystem, Convergencia: Revista de ciencias sociales, 68, 125-149.

Escaño, C. (2017). Free digital culture, commons and education. Development of the educational values of the arts and free culture on the web, Doctoral Thesis, Universidad Complutense de Madrid. http://e-spacio.uned.es/fez/eserv/tesisuned:ED-Pg-CyEEDJcescano/ESCANO_GONZALEZ_JoseCarlos_Resumen_Tesis.pdf

Legaz, I., Morales, R. (2018). Wiki spaces as a teaching resource in Higher Education. IV International Virtual Congress on Pedagogical Innovation and Educational Praxis. INNOVAGOGÍA 2018. http://hdl.handle.net/10433/6411.

Lucero, M.M. (2003). Between collaborative work and collaborative learning, Revista Iberoamericana de Educación, 33. Doi: 10.35362/rie3312923.

Ménez, E. (2015). Open culture. Shared knowledge, Yearbook ThinkEPI, 9, 1, 126-131. Doi:10.3145/thinkepi.2015.30. 
Meseguer-Artola, A (2015). Wikipedia at University: A guide to good practice, Oikonomics: Revista de Economía Empresa y Sociedad, 3.

Romero, E., Robinson, N. (2015). Social laboratories in universities. Innovation and impact at Medialab UGR. Comunicar: Revista cientifica iberoamericana de comunicación y educación, 51, 29-38.

Ruíz, J.M (2016). The role of the medialab in Ecuadorian public Higher Arts Education: first experiences in art, science and technology. Teknokultura. Revista De Cultura Digital Y Movimientos Sociales, 13(1), 97-116. https://doi.org/10.5209/rev_TK.2016.v13.n1.51773.

Toledano, B. (2020). How Google is killing Wikipedia (16 June 2020). Retrieved from https://www.elmundo.es/tecnologia/2020/06/16/5ee72224fc6c83d71a8b45e3.html

Villarroel, J.D. (2007). Didactic uses of the wiki in secondary education. Ikastorratza, eJournal of Didactics, 1, 1-7. http://www.ehu.es/ikastorratza/1_alea/wikia.pdf 